\title{
Obtención de embriones en fase cotiledonar de Café Robusta \\ (Coffea canephora) con el empleo de un sistema de \\ inmersión temporal, mediante la técnica de embriogénesis somática a partir de segmentos foliares
}

\author{
Gabriela Paredes, Cristian Peña y Mónica Jadán \\ Departamento de Ciencias de la Vida, Carrera de Ingeniería en Biotecnología, Laboratorio de Cultivo de Tejidos, \\ ESPE, Sangolquí, Ecuador \\ magabriela_paredes@yahoo.com
}

Recibido: 02, 06, 2013; aceptado: 08, 10, 2013

RESUMEN.- En el presente trabajo se llevó a cabo la estandarización de la fase de establecimiento, en donde la concentración de cloro $1.5 \%$ y una inmersión de 20 minutos, resultó ser efectiva en cuanto a bajos porcentajes de contaminación y oxidación. Para la fase de inducción de callo se utilizó el medio M\&S (Murashige \& Skoog) con $3 \%$ de sacarosa y $7 \%$ de agar, con diferentes concentraciones de 2,4-D (ácido-2,4- diclorofenilacético), BAP (bencilaminopurina) y KIN (Kinetina); el mejor medio resultó ser: M\&S adicionado con $0.5 \mathrm{mgL}^{-1}$ de 2,4-D y $2 \mathrm{mgL}^{-1}$ de KIN. Los embriones se desarrollaron en medio M\&S a la mitad de la concentración sin reguladores de crecimiento; dicho medio se probó también en forma líquida en tarrinas (sistema de inmersión casero) y en un sistema de inmersión temporal automatizado (SIT), en donde el primero mostró crecimiento de embriones ya que a los 20 días se visualizaron embriones en estado globular y a las 12 semanas de cultivo se lograron obtener 611 embriones, de los cuales 15 presentaron el estado cotiledonar. El Sistema de Inmersión Temporal automatizado no mostró resultado alguno.

PALABRAS CLAVES: embriogénesis, estado cotiledonar, medio líquido, sistema de inmersión temporal

ABSTRACT.- Standard methods were developed to obtain cotyledon-stage embryos of Coffea canephora in the laboratory. The stablishment phase was standarized using a chlorine concentration of $1.5 \%$ and 20 minutes immersion time. This method was effective because it reduced contamination and produced low percentages of oxidation. In the callus induction phase, the medium used was M\&S (Murashige \& Skoog) with saccharose (3\%) and agar $(7 \%)$. We tested different concentrations of 2,4-D (2,4- dichlorophenilacetic acid), 
BAP (benzylaminopurine) and KIN (kinetin). The best medium was: M\&S with $0.5 \mathrm{mg} /$ L of 2,4-D and $2 \mathrm{mg} / \mathrm{L}$ of KIN. The embryos were grown in M\&S medium at half strength without growth regulators. This medium was also tested as a liquid in large tubs in two systems, the home immersion system and Automated Temporary Immersion System (TIS). There was embryo growth after 20 days in the home inmmersion system. We produced globular stage embryos in the system and after 12 weeks we had 611 embryos, 15 of these embryos were in the cotyledon stage. The automated temporary immersion system did not produced embryos.

KEYWORDS: cotyledonar stage, embryogenesis, liquid medium, temporary immersion system

\section{INTRODUCCIÓN}

En el Ecuador el café está dentro de los cinco productos más exportados. Para noviembre del 2012 alcanzó un total de 180 mil quintales exportados (Pro Ecuador, 2013). Ecuador es uno de los 14 países que tiene producción mixta, es decir, cultiva las dos especies comerciales: arábiga (Coffea arabica) y robusta (Coffea canephora); esta última es la de mayor interés debido a la resistencia contra la broca del café y porque puede cultivarse en suelos bastante pobres en nutrientes (Delgado et al., 2002).

Es por eso que la introducción de métodos biotecnológicos como herramienta para la producción masiva de plantas, ha sido de utilidad principalmente en cultivos perennes, como el café. Un importante método de propagación in vitro de plantas de C. canephora es la embriogénesis somática, la misma que consiste en el desarrollo de embriones sin la fusión de gametos, que permitieron la propagación masiva acelerada y se convirtieron en un gran potencial de exploración (Rezende et al., 2003).

La embriogénesis somática constituye una importante alternativa respecto a la forma tradicional de cultivo de café, ya que permite aumentar la tasa de multiplicación y la propagación rápida de plantas seleccionadas (González et al., 2004).

Los primeros embriones somáticos de cafeto fueron obtenidos a principios de 1970 por Staritsky, al emplear secciones de hojas de ramas ortotrópicas (crecimiento de las ramas o los brotes principales de manera vertical) jóvenes de C. canephora (Dublin, 1991). En los últimos años, se ha incrementado la regeneración de plantas por esta vía y en particular el cultivo de células en suspensión (Cevallos et al., 2002; de Feria et al., 2005; Etienne-Barry et al., 1999; Montes et al., 1995; Zamarripa et al., 1991). La utilización de los biorreactores ha permitido que sea la vía más promisoria para el proceso de micropropagación 
a gran escala, particularmente para la embriogénesis somática, ya que durante los últimos 15 años en varios países, los biorreactores han sido usados en café para optimizar la regeneración masiva de embriones somáticos a partir de tejido embriogénico (Etienne et al., 2006). En el Ecuador todavía se siguen realizando ensayos para determinar el mejor método para inducir embriones y poder obtenerlos a gran escala.

De allí que los objetivos de este estudio consisten en estandarizar el protocolo de desinfección de hojas de café robusta (Coffea canephora) y los medios de cultivo para la inducción de callo y embriones, así como también determinar la frecuencia de inmersión de los callos en el Sistema de Inmersión Temporal para la producción de embriones.

\section{MATERIALES Y MÉTODOS}

A partir de 10 plantas jóvenes de invernadero de aproximadamente 5 meses de edad, se recolectaron 3 hojas de las partes más cercanas al meristema apical. Previo a esto se realizó un tratamiento fitosanitario en invernadero que consistió en la aplicación mediante aspersión de un fungicida sistémico Amistar $\left(1 \mathrm{gL}^{-1}\right)$ en las plantas madre una vez al día por 3 días seguidos antes de la recolección de las hojas.

Desinfección.- Las hojas fueron lavadas en una corriente de agua por un minuto para eliminar el fungicida sistémico Amistar y las impurezas de la hoja. Se las sumergió durante $10 \mathrm{~min}$ en el detergente comercial DEJA (C) al $1 \%$ p/v con la adición de $0.1 \%$ Tween 20; luego se las colocó en diferentes concentraciones de cloro (1 y $1.5 \%$ v/v) y a diferentes tiempos de inmersión (15 y $20 \mathrm{~min}$ ), finalmente se realizaron 3 enjuagues en cámara con agua destilada estéril. Con un bisturí, se cortaron segmentos de hoja de diferentes tamaños: 0.25 y $1 \mathrm{~cm}^{2}$, según la Tabla 1 y

Tabla 1

Tratamientos de desinfección para hojas de Coffea canephora

\begin{tabular}{cccc} 
Tratamiento & $\begin{array}{c}\text { Concentración } \\
\text { de cloro }(\%)\end{array}$ & $\begin{array}{c}\text { Tratamiento } \\
(\mathbf{m i n})\end{array}$ & $\begin{array}{c}\text { Tamaño de hoja } \\
\left(\mathbf{c m}^{\mathbf{2}}\right)\end{array}$ \\
\hline 1 & 1 & 15 & 0.25 \\
2 & 1 & 15 & 1 \\
3 & 1 & 20 & 0.25 \\
4 & 1 & 20 & 1 \\
5 & 1.5 & 15 & 0.25 \\
6 & 1.5 & 15 & 1 \\
7 & 1.5 & 20 & 0.25 \\
8 & 1.5 & 20 & 1 \\
\hline
\end{tabular}


se colocaron en frascos con medio decultivo a los 15 días de cultivo, se determinó la sólido con las sales de Murashige y Skoog presencia de colonias bacterianas o fúngicas (1962), sacarosa $3 \%$ p/v y $7 \mathrm{gL}^{-1}$ de agar. y se le asignó el valor de "1", mientras que a Las condiciones de cultivo fueron a $25 \pm 1^{\circ}$ un explante no contaminado se le asignó el C, humedad relativa 50-60\% sin luz directa. valor de “0”, según la Figura 1.

Se evaluaron contaminación y oxidación

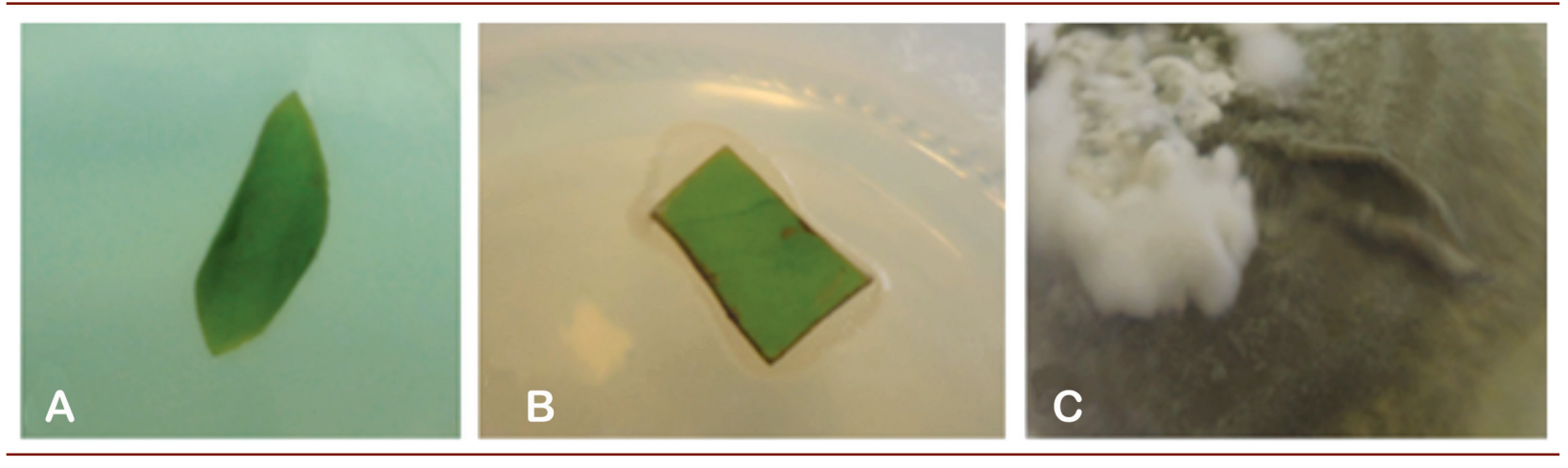

Figura 1. (A) Explante viable (0). (B) Explante con contaminación bacteriana (1). (C) Explante con contaminación fúngica (1).

Para la oxidación se determinó si un oxidado se le asignó el valor de "0", según explante estaba oxidado y se le asignó el la Figura 2.

valor de " 1 ", mientras que a un explante no

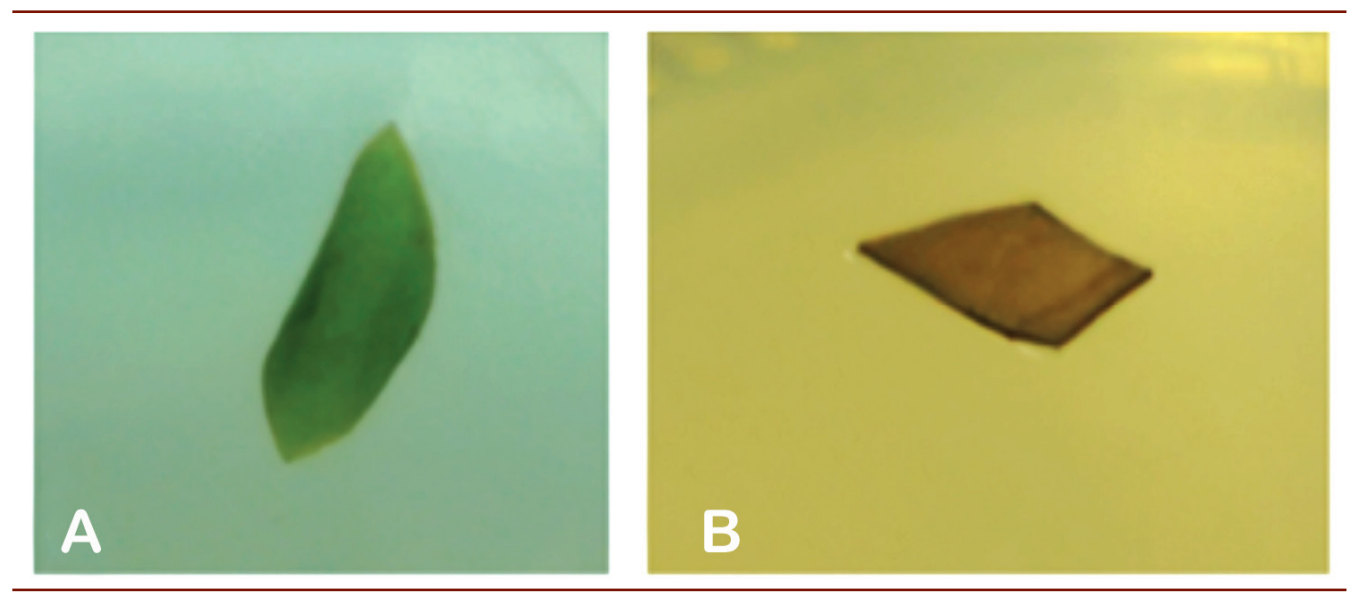

Figura 2. (A) Explante viable (0). (B) Explante oxidado (1).

Se realizaron 10 repeticiones por experimental fue un segmento de hoja por cada tratamiento, en donde la unidad frasco. 
Medio de inducción de callo.- Una vez determinado el mejor tratamiento de desinfección, se dio inicio a la fase de inducción de callo, en donde los explantes fueron colocados en frascos con $30 \mathrm{ml}$ de medio de cultivo con el haz en contacto con este. El medio de cultivo contenía las sales de Murashige y Skoog (1962) y vitaminas de Morel y Wetmore (1951), sacarosa $3 \%$ $\mathrm{p} / \mathrm{v}$ y agar $8 \mathrm{gL}^{-1}$. Ocho medios de inducción de callo (I 1-I 8) fueron evaluados: la com- binación factorial de dos concentraciones de ácido 2,4-D (0.5 y $\left.1 \mathrm{mgL}^{-1}\right)$ con dos concentraciones de Bencilaminopurina, BAP (4 y $8 \mathrm{mgL}^{-1}$ ) y dos concentraciones de Kinetina, 6-furfurilaminopurina, KIN (2 y $4 \mathrm{mgL}^{-1}$ ), más un tratamiento control carente de hormonas como se indica en la Tabla 2. Se realizaron 10 repeticiones por tratamiento. Se incubaron los explantes a $27 \pm 1^{\circ} \mathrm{C}$ de temperatura, 50-60\% de humedad relativa y en completa oscuridad.

\section{Tabla 2}

Tratamiento para la inducción de callo

\begin{tabular}{cccc} 
Tratamiento & 2,4-D $\left(\mathbf{m g ~ L}^{-1}\right)$ & BAP $\left(\mathrm{mg} \mathrm{L}^{-1}\right)$ & Kin $\left(\mathrm{mg} \mathrm{L}^{-1}\right)$ \\
I 0 & 0 & 0 & 0 \\
I 1 & 0.5 & 4 & - \\
I 2 & 0.5 & 8 & - \\
I 3 & 1 & 4 & - \\
I 4 & 1 & 8 & - \\
I 5 & 0.5 & - & 2 \\
I 6 & 0.5 & - & 4 \\
I 7 & 1 & - & 2 \\
I 8 & 1 & - & 4 \\
\hline
\end{tabular}

Se evaluó el índice de crecimiento de se establecieron niveles del 0 al 4: el "0" callo con la prueba de Tukey y el tipo de equivale al $0 \%$ de crecimiento del callo y callo a los 20 y 45 días de cultivo, mediante el " 4 " al 90-100 \% de crecimiento, como se observación para el índice de crecimiento indica en Tabla 3 y Figura 3.

\section{Tabla 3}

Niveles que determinan la formación de callo

\section{Niveles Formación de callo}

\begin{tabular}{cc}
0 & $0 \%$ \\
1 & $10-30 \%$ \\
2 & $35-55 \%$ \\
3 & $60-85 \%$ \\
4 & $90-100 \%$ \\
\hline
\end{tabular}




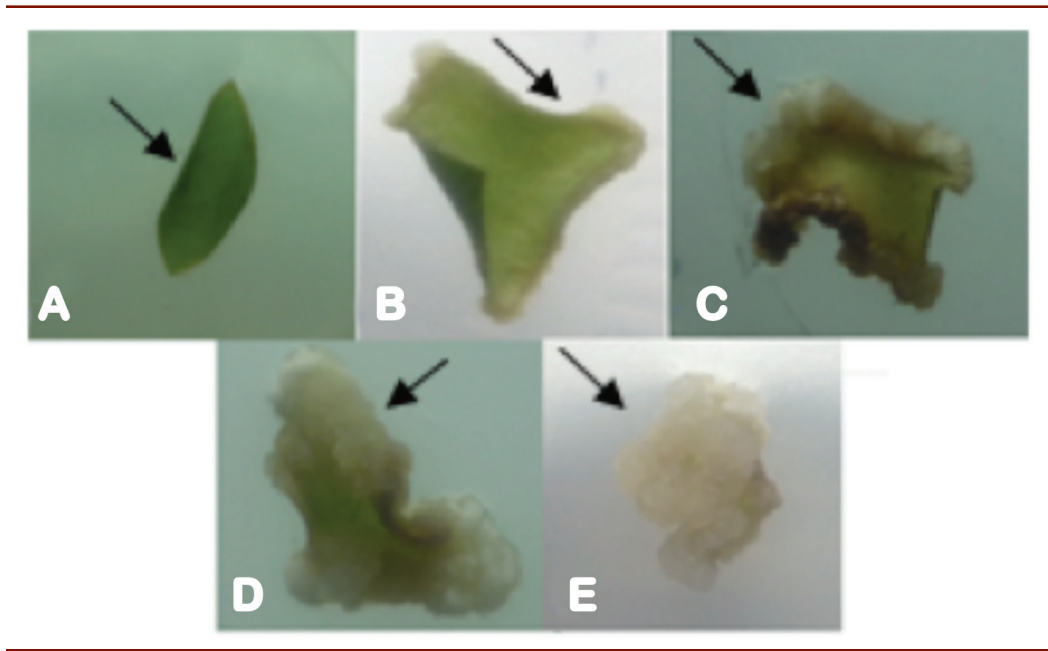

Figura 3. (A) Nivel 0. (B) Nivel 1. (C) Nivel 2. (D) Nivel 3, (E) Nivel 4.

El tipo de callo friable o no friable se caseína hidrolizada, $20 \mathrm{mgL}^{-1}$ de tiamina, determinó de manera visual, un callo $200 \mathrm{mgL}^{-1}$ de inositol, $20 \mathrm{mgL}^{-1}$ de glicina, friable es de apariencia seca, compacta, de $60 \mathrm{mgL}^{-1}$ de adenina, sacarosa $3 \% \mathrm{p} / \mathrm{v}$ y coloración amarillo-blanquecina, según la $5 \mathrm{gL}^{-1}$ de agar. Ocho medios de inducción escala planteada por Pérez (1998). de embriones (E1-E8) fueron probados; estos resultaron de la combinación

Medio de inducción de embriones.- factorial de dos concentraciones de Ácido Establecido el mejor medio de inducción $\alpha$-naftalenacético, ANA ( 0.1 y 1 mgL m $\left.^{-1}\right)$ de callo y después de 45 días de cultivo, con dos concentraciones de $\mathrm{KNO}_{3}(0.126$ y los callos se cultivaron en el medio de $1.26 \mathrm{mgL}^{-1}$ ) y dos concentraciones de KIN inducción de embriones, basado en lo $\left(0.5\right.$ y $\left.5 \mathrm{mgL}^{-1}\right)$, más un tratamiento control propuesto por Etienne (2005) sales de carente de hormonas (Tabla 4). Murashige y Skoog (1962), $200 \mathrm{mgL}^{-1}$ de

\section{Tabla 4}

Tratamientos para la inducción de embriones

\begin{tabular}{cccc} 
Tratamiento & ANA $\left(\mathrm{mg} \mathrm{L}^{-1}\right)$ & KNO3 $_{\left(\mathrm{mg} \mathrm{L}^{-1}\right)}$ & $\mathrm{KIN}_{\left(\mathrm{mg} \mathrm{L}^{-1}\right)}$ \\
\hline MS $/ 2$ & 0 & 0 & 0 \\
E0 & 0 & 0 & 0 \\
E1 & 0.1 & 0.126 & - \\
E2 & 0.1 & 1.26 & - \\
E3 & 1 & 0.126 & - \\
E4 & 1 & 1.26 & - \\
E5 & 0.1 & - & 0.5 \\
E6 & 0.1 & - & 5 \\
E7 & 1 & - & 0.5 \\
E8 & 1 & - & 5 \\
\hline
\end{tabular}


Se realizaron 10 repeticiones por tratamiento con un explante por frasco. Se incubaron a $27 \pm 1^{\circ} \mathrm{C}$ de temperatura, $50-60 \%$ de humedad relativa y con un fotoperíodo de $16 \mathrm{~h}$ luz.

En esta etapa se evaluaron como variables: el tiempo en el cual se forman las estructuras globulares (días en los cuales se observan embriones en fase globular) y la capacidad embriogénica que se determinó al contar la cantidad de embriones somáticos obtenidos en estado globular dividido para el número total de callos (por tratamiento) por 100. La variable capacidad embriogénica se analizó a las 8 y 12 semanas después de la siembra.

\section{Inducción de embriones en medio} líquido.- Una vez estandarizado el medio de cultivo para inducción de embriones en medio sólido, se evaluó esa misma composición en consistencia líquida. Se probó el medio de cultivo líquido en 2 sistemas de inmersión, uno casero (tarrinas plásticas) y otro automatizado (frascos de vidrio transparentes).

El sistema de inmersión temporal casero constó de 2 tarrinas de plástico de 2 tamaños; a la más pequeña se le hizo cuatro agujeros y se la colocó dentro de la más grande y se tapó la cámara (Figura 4);

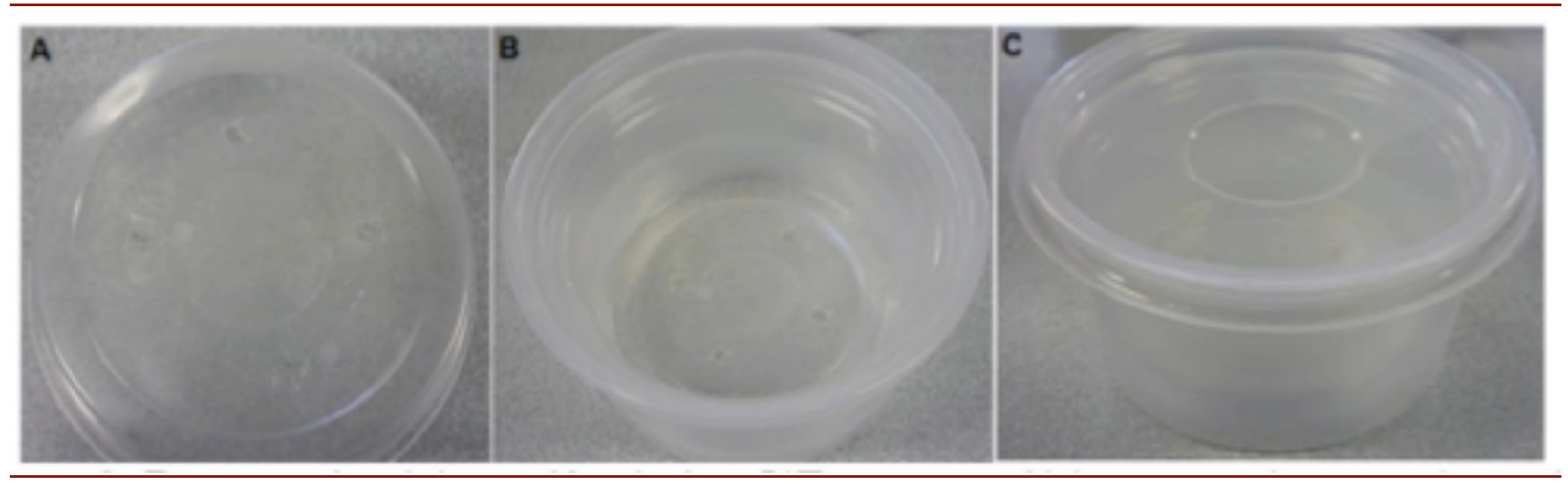

Figura 4. Proceso de elaboración de los SIT caseros. A) Agujeros en la tarrina pequeña. B) Colocar la tarrina pequeña dentro de la grande. C) Colocar la tapa de la tarrina grande.

en la tarrina pequeña se añadió $1 \mathrm{~g} \mathrm{MF} \mathrm{L}^{-1}$ (gramo de masa fresca por litro de medio de cultivo) y se colocó en un agitador orbital a 110 rpm. Se evaluó el tiempo en el cual se forman las estructuras globulares (días en los cuales se observen embriones en fase globular) y la capacidad embriogénica que se determinó al contar la cantidad de embriones somáticos obtenidos en estado globular dividido para el número total de embriones por 100. La variable capacidad embriogénica se analizó a las 8 y 12 semanas después de la siembra.

En el sistema de inmersión temporal automatizado, el medio de cultivo de inducción de embriones estandarizado fue adicionado a los biorreactores con el fin de evaluar 3 frecuencias de inmersión con un tiempo de $1 \mathrm{~min}$, según la Tabla 5. 
Tabla 5

Tratamientos para obtención de embriones en el Sistema de Inmersión Temporal

\begin{tabular}{ccc} 
Tratamiento & $\begin{array}{c}\text { Tiempo de Inmersión } \\
(\mathbf{m i n})\end{array}$ & $\begin{array}{c}\text { Frecuencia } \\
\text { (horas) }\end{array}$ \\
\hline 1 & 1 & 8 \\
2 & 1 & 10 \\
3 & 1 & 12 \\
\hline
\end{tabular}

\section{RESULTADOS Y DISCUSIÓN}

Desinfección.- Los resultados obtenidos de la variable contaminación, permitieron determinar que el mejor porcentaje de descontaminación se encontró en la concentración de $1.5 \% \mathrm{v} / \mathrm{v}$ de hipoclorito de sodio. Es por esto que el tratamiento 7 indicado en la Tabla 1, es considerado el mejor, lo cual se asemeja con el trabajo realizado por Santana et al., (2004) en donde el proceso de desinfección establecido consta de la inmersión en hipoclorito de sodio $1.5 \%$ $\mathrm{v} / \mathrm{v}$ por $20 \mathrm{~min}$. El tamaño de explante no influyó al momento de evaluar esta variable ya que según las pruebas de chi-cuadrado que se realizaron al tomar o no en cuenta el tamaño del explante, arrojaron el mismo resultado de independencia en cuanto a la concentración de cloro.

En los resultados obtenidos para la variable oxidación cuando se utizaron concentraciones de 1 y $1.5 \%$ v/v de hipoclorito de sodio, se observó que el tamaño del explante influye en la presencia de oxidación y es por eso que bajos porcentajes de oxidación se encuentran a la concentración del $1 \%$ de hipoclorito de sodio y un tamaño de hoja de $1 \mathrm{~cm}^{2}$, sin importar el tiempo de inmersión; este hecho mostró que los mejores tratamientos son los dos primeros propuestos en la Tabla 1.

La Figura 5 muestra un resumen de las variables evaluadas en cada uno de los tratamientos de desinfección, donde se evidencia que los tratamientos $6(1.5 \%$ - 15 $\left.\min -1 \mathrm{~cm}^{2}\right)$ y $8\left(1.5 \%-20 \mathrm{~min}-1 \mathrm{~cm}^{2}\right)$ son los que presentaron mayor porcentaje de explantes no contaminados y no oxidados (el tratamiento 8 es igual al utilizado por Santana et al. 2004). 


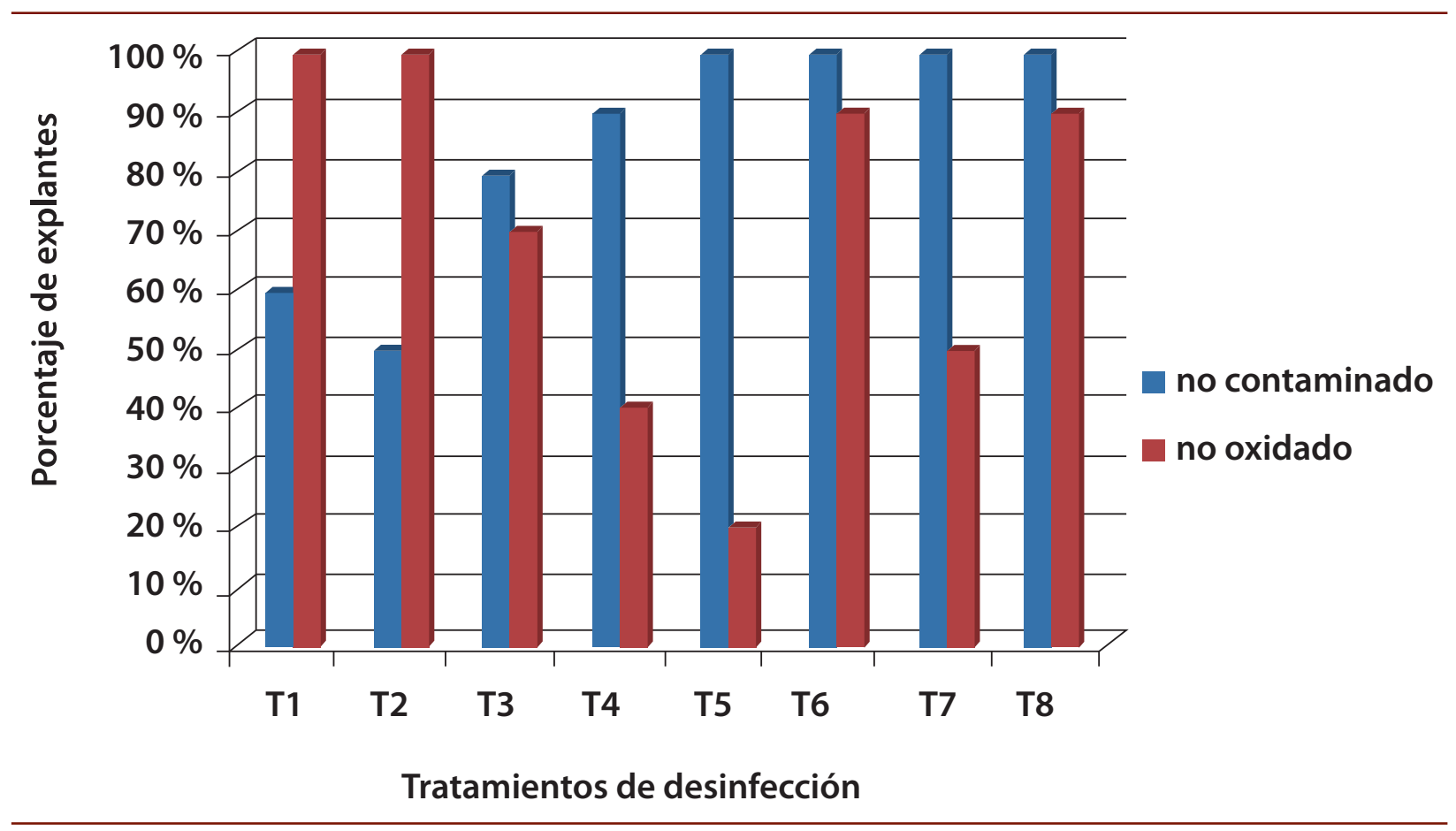

Figura 5. Porcentaje de explantes no contaminados y no oxidados con respecto al tratamiento de desinfección.

Inducción de callo.- González et al., (2008), Gatica et al. (2007), Santana et al. (2004) y Rezende et al. (2003), en la etapa de inducción de callo, evaluaron diferentes concentraciones deauxinasy citoquininasen distintos genotipos de café. En este trabajo se pudo evidenciar que para la variedad de café robusta utilizada, con la concentración de 2,4-D $\left(0.5 \mathrm{mgL}^{-1}\right)$ y KIN $\left(2 \mathrm{mgL}^{-1}\right)$ se pudo obtener gran crecimiento de callo (nivel 4) y la friabilidad deseada del mismo, pero no se obtuvo un alto porcentaje de desarrollo de callo embriogénico que es lo que se esperaba para la obtención de embriones somáticos; ya que como menciona Samson et al. (2006) la concentración de los reguladores de crecimiento y especialmente el balance entre las auxinas y citocininas es un factor clave en la inducción de callo y la iniciación de la embriogénesis somática. A diferencia de los resultados obtenidos por Quiroz-Figueroa et al., (2002), ya que en su trabajo al utilizar $1 \mathrm{mgL}^{-1}$ de 2,4-D y 2 $\mathrm{mgL}^{-1}$ de KIN en Coffea arabica obtuvieron $68 \%$ de callos embriogénicos mientras que en este trabajo solo se obtuvo un $10 \%$ de callos embriogénicos y el resto fueron no embriogénicos. De esta manera se probó la existencia de un control genético en el comportamiento in vitro de los clones (Santana, 1993).

Para el índice de crecimiento, de acuerdo con la prueba de Tukey a los 20 días se encontraron cuatro grupos estadísticos (A, B, C y D), donde se observa que el mejor tratamiento, el que tiene la mayor media, es el I5, que se muestra en la Tabla 6. 


\section{Tabla 6}

Prueba de Tukey para la variable índice de crecimiento con respecto a la interacción de las hormonas 2,4-D - BAP y 2,4-D - KIN a los 20 y 45 días de cultivo

\begin{tabular}{|c|c|c|c|c|c|c|c|}
\hline Test: Tukey & Alfa $=0.05$ & $\begin{array}{c}\text { DMS: } \\
0.57714\end{array}$ & & & & & \\
\hline $\begin{array}{l}\text { Error: } \\
0.1630\end{array}$ & gL: 81 & $\begin{array}{l}20 \text { días de } \\
\text { cultivo }\end{array}$ & & & & & \\
\hline Tratamiento & Medias & $\mathrm{n}$ & EE & & & & \\
\hline $\mathrm{IO}$ & 0 & 10 & 0.13 & $\mathrm{~A}$ & & & \\
\hline I1 & 1 & 10 & 0.13 & & B & & \\
\hline $\mathrm{I} 2$ & 1.2 & 10 & 0.13 & & B & $\mathrm{C}$ & \\
\hline I7 & 1.2 & 10 & 0.13 & & $\mathrm{~B}$ & $\mathrm{C}$ & \\
\hline I4 & 1.3 & 10 & 0.13 & & B & C & \\
\hline I8 & 1.4 & 10 & 0.13 & & B & $\mathrm{C}$ & $\mathrm{D}$ \\
\hline I3 & 1.5 & 10 & 0.13 & & B & C & $\mathrm{D}$ \\
\hline I6 & 1.7 & 10 & 0.13 & & & $\mathrm{C}$ & $\mathrm{D}$ \\
\hline I5 & 1.9 & 10 & 0.13 & & & & $\mathrm{D}$ \\
\hline
\end{tabular}

\begin{tabular}{|c|c|c|c|c|c|c|c|c|}
\hline Test: Tukey & Alfa $=0.05$ & $\begin{array}{c}\text { DMS: } \\
\mathbf{0 . 8 3 4 5 4}\end{array}$ & & & & & & \\
\hline $\begin{array}{l}\text { Error: } \\
0.3407\end{array}$ & gL: 81 & $\begin{array}{l}45 \text { días de } \\
\text { cultivo }\end{array}$ & & & & & & \\
\hline Tratamiento & Medias & $\mathrm{n}$ & $\mathrm{EE}$ & & & & & \\
\hline I0 & 0 & 10 & 0.18 & A & & & & \\
\hline I4 & 1.4 & 10 & 0.18 & & B & & & \\
\hline $\mathrm{I} 2$ & 2.3 & 10 & 0.18 & & & $\mathrm{C}$ & & \\
\hline I1 & 2.6 & 10 & 0.18 & & & $\mathrm{C}$ & $\mathrm{D}$ & \\
\hline I3 & 2.8 & 10 & 0.18 & & & C & $\mathrm{D}$ & \\
\hline I7 & 3.3 & 10 & 0.18 & & & & $\mathrm{D}$ & $E$ \\
\hline I8 & 3.3 & 10 & 0.18 & & & & $\mathrm{D}$ & E \\
\hline I6 & 3.9 & 10 & 0.18 & & & & & E \\
\hline I5 & 4 & 10 & 0.18 & & & & & $E$ \\
\hline
\end{tabular}

A los 45 días de cultivo se encontraron la concentración de 2,4-D - BAP y 2,4-D cinco grupos estadísticos (A, B, C, D y E), KIN (20 días de cultivo) y el tipo de callo, al mostrar que los mejores tratamientos, se evaluó mediante un gráfico que muestra es decir los que presentan la media más el porcentaje de friabilidad existente en alta son 15 y I6 que pertenecen al grupo cada uno de los tratamientos, en donde E, con lo cual se puede concluir que el se observa que la mayor cantidad de callo tratamiento 5 es el mejor. La relación entre friable se encuentra en los tratamientos I7 e 
I8 indicados en la tabla 2. La relación entre de porcentaje, en donde se observa que la la concentración de 2,4-D-BAP y 2,4-D- mayor cantidad de callo friable se encuentra KIN (45 días de cultivo) y el tipo de callo, en los tratamientos I5, I6, I7 e I8, según la se evaluó también mediante un gráfico Figura 6.

\section{0 días de cultivo}

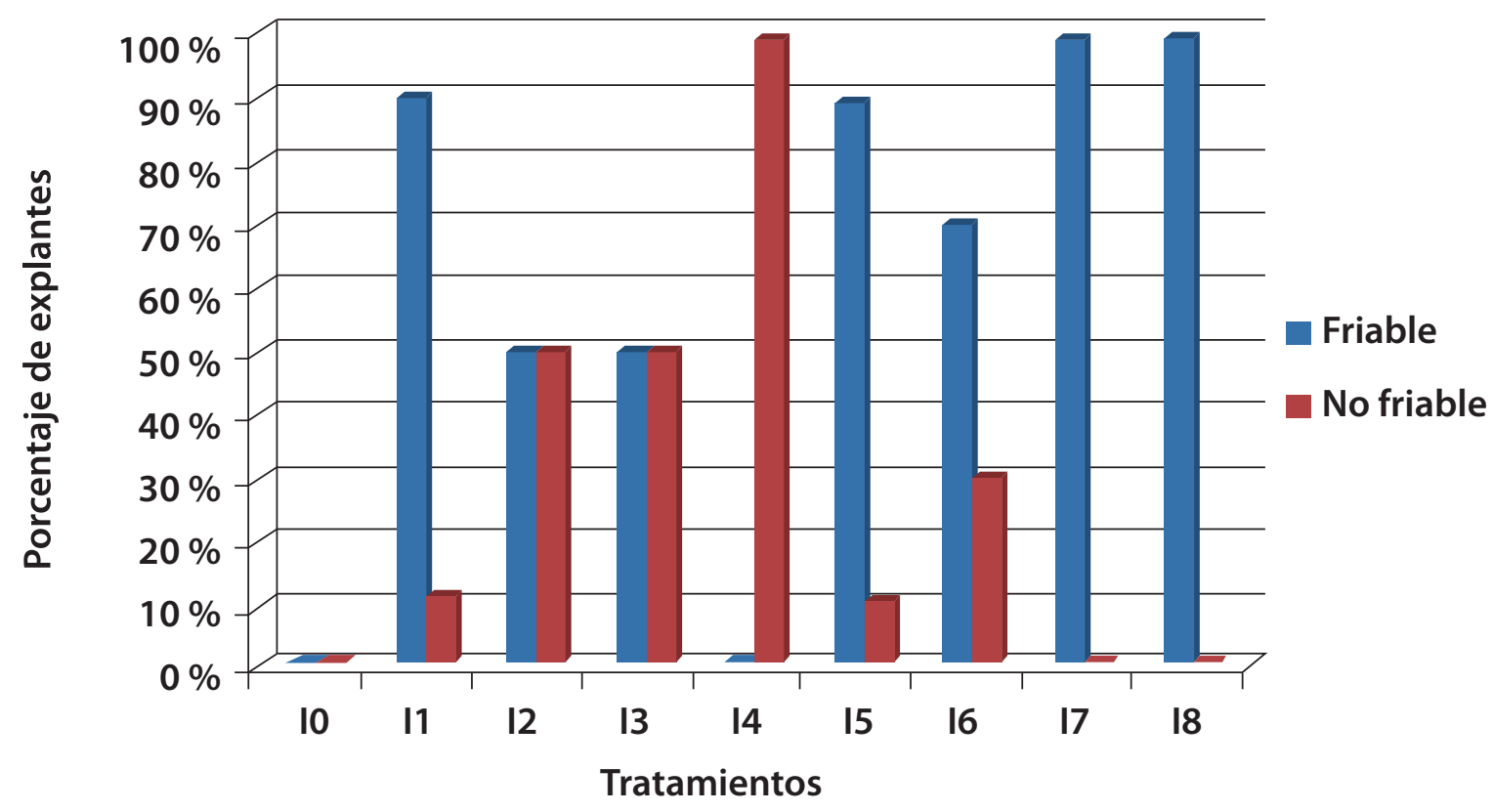

\section{5 días de cultivo}

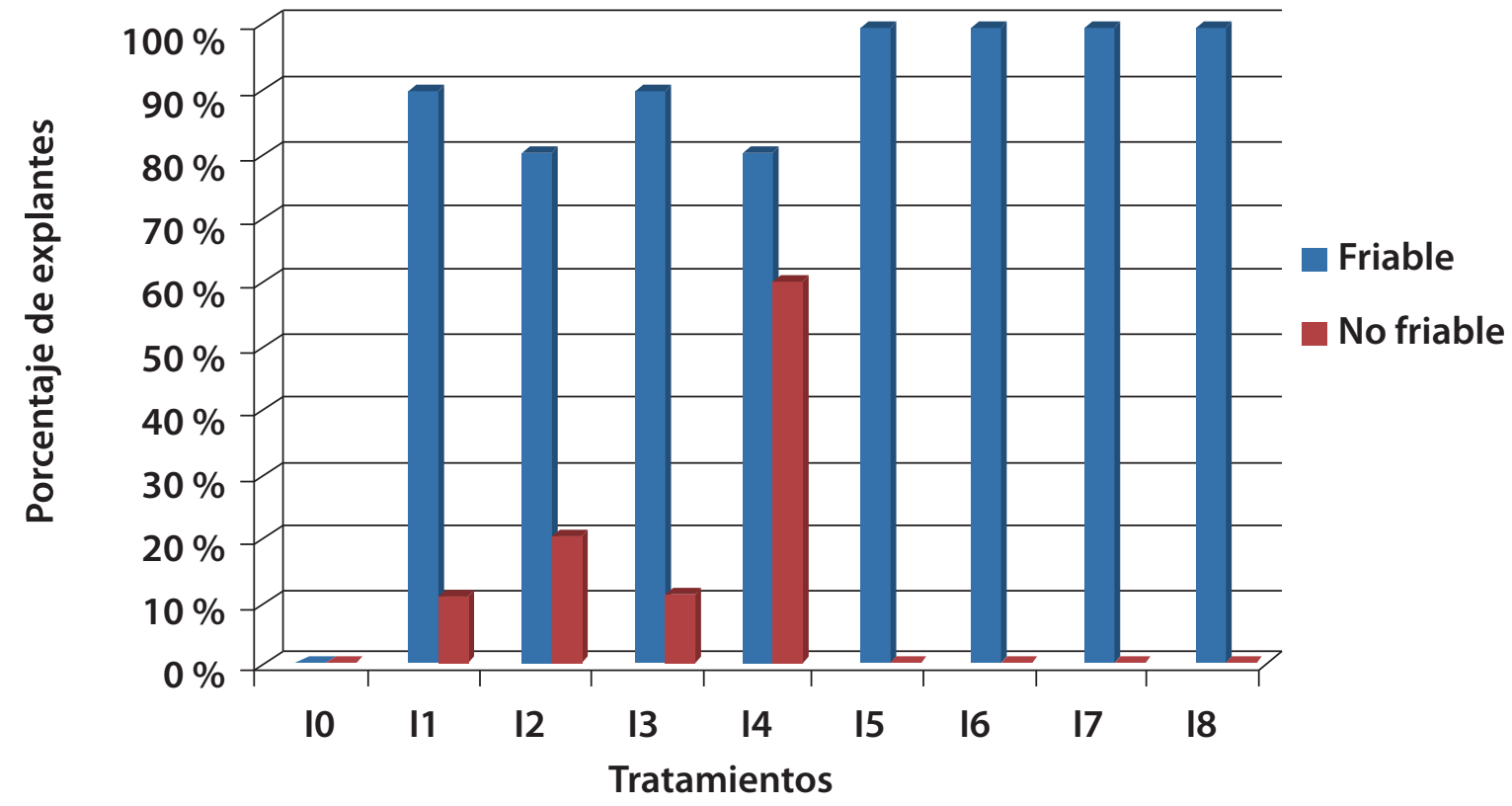

Figura 6. Porcentaje de callos friables y no friables encontrados al utilizar diferentes combinaciones de 2,4-D-BAP y 2,4-D-KIN, después de 20 y 45 días de cultivo. 
La combinación de $0.5 \mathrm{mgL}^{-1}$ de 2,4D y 2 y $4 \mathrm{mgL}^{-1}$ de KIN a los 45 días de evaluación según la figura 6 y la tabla 6, muestran que presentaron un índice de crecimiento nivel 4 y hubo el $100 \%$ de explantes que presentaron callos friables, que se utilizan en este presente trabajo la combinación de 2,4-D $\left(0.5 \mathrm{mgL}^{-1}\right)$ y KIN (2 $\left.\mathrm{mgL}^{-1}\right)$. En estudios como el de Cevallos et al., (2002) se verificó que las frecuencias más altas de los callos embriogénicos fueron observados cuando la auxina estuvo presente en un cultivo primario asociado con la kinetina a las mismas concentraciones mencionadas anteriormente.

Inducción de embriones.-Para inducir la formación del embrión somático a partir de los proembriones, es necesario adicionar al medio de cultivo, bajas concentraciones de auxina, auxinas menos fuertes $o$ incluso no adicionar auxinas (Nomura y Komamine, 1995). Otro factor a considerar en la respuesta a la embriogénesis es el cambio estacional, ya que variaciones de temperatura, humedad y precipitaciones provocan cambios fisiológicos en las plantas de invernadero que influyen el comportamiento in vitro de los explantes (Pírela y Mogollón, 1996).

Según Dublin (1991) para la activación de la embriogénesis somática de alta frecuencia (ESAF) y su eficacia es necesaria la adición de 2,4-D en combinación con KIN durante el cultivo primario. Además la remoción de 2,4-D y la disminución de las concentraciones de ANA y KIN, en el medio de inducción de embriogénesis, se consideran esenciales para el desarrollo de los embriones somáticos de la ESAF en Coffea sp., lo cual fue comprobado por Moncada et al. (2005), González (2003) y Cevallos et al. (2002); sin embargo, en el presente trabajo no se corroboró esto, ya que en ninguno de los tratamientos probados con combinaciones de ANA y KIN en 8 meses de cultivo presentó producción de embriones.

\section{El momento de aparición de} los primeros embriones, las tasas de embriogénesis (porcentaje de explantes que producen embriones) y el número de embriones producidos por explante dependen de varios factores; entre ellos, la combinación de auxina/citocinina utilizadas en la etapa de inducción de callo, la duración de dicha etapa, el origen del explante y el estado fisiológico de la planta madre (Dublin, 1991).

Del $10 \%$ de callos embriogénicos se lograron obtener embriones a los 8 meses de cultivo en el medio M\&S a la mitad de la concentración y sin la presencia de reguladores de crecimiento (medio de inducción de callo), así como González et al., (2008), Samson et al., (2006) y Roca y Mroginski (1991), que emplearon también en sus estudios el mismo medio basal para la obtención de embriones somáticos. En el presente trabajo a las 8 semanas de cultivo se obtuvieron 45 embriones y a las 12 semanas se obtuvieron 61 (Tablas 7 y 8). 


\section{Tabla 7}

Conteo de embriones en todos los estados encontrados a las 8 semanas de visualizado estructuras embrionarias en medio sólido

\begin{tabular}{cc}
$\begin{array}{c}\text { Estado } \\
\text { embrionario }\end{array}$ & $\begin{array}{c}\text { \# de } \\
\text { embriones }\end{array}$ \\
Globular & 23 \\
Corazón & 2 \\
Torpedo & 14 \\
Cotiledonar & 1 \\
Anormales & 5 \\
\hline TOTAL & 45 \\
\hline
\end{tabular}

\section{Tabla 8}

Conteo de embriones en todos los estados encontrados a las 12 semanas de visualizado estructuras embrionarias en medio sólido

\begin{tabular}{cc}
$\begin{array}{c}\text { Estado } \\
\text { embrionario }\end{array}$ & $\begin{array}{c}\# \text { de } \\
\text { embriones }\end{array}$ \\
Globular & 13 \\
Corazón & 0 \\
Torpedo & 26 \\
Cotiledonar & 10 \\
Anormales & 7 \\
Sólo eje radical & 3 \\
Sólo brote & 2 \\
\hline TOTAL & 61 \\
\hline
\end{tabular}

Inducción de embriones en medio líquido.- El uso de medio líquido tiene muchas ventajas como por ejemplo: mayor contacto del explante con el medio nutritivo, lo cual permite el intercambio gaseoso dentro del recipiente que ayuda a mejorar el crecimiento y desarrollo de los explantes, al mismo tiempo que es considerado como una técnica ideal para la producción en masa de plántulas y embriones, que simplifican los cambios de medio. Además, a nivel fisicoquímico la difusión de los elementos nutritivos es aproximadamente de dos a cuatro veces más alta que el medio gelificado (Girón, 1998); es por esto que se decidió ensayar la formación de embriones somáticos en Sistemas de Inmersión ya que en muchos estudios ha dado resultados con un alto porcentaje de producción.

En el Sistema de Inmersión Temporal Automatizado (SIT) no se obtuvo resultado 
alguno en cuanto a la producción de embriones; esto se debe a que los callos utilizados no eran embriogénicos, ya que no se realizó un estudio histológico con el cual se garantice el estado embriogénico de los callos y poder obtener un mejor resultado al utilizar este Sistema. Además que el Sistema Automatizado no fue el adecuado para el desarrollo de la embriogénesis, ya que en estudios como el de Gatica et al. (2007), Barreto (2003), Etienne y Berthouly (2002) y Girón (1998), se utilizó el Sistema de Inmersión Temporal (RITA), el cual tiene un soporte especial que permite que los embriones estén en contacto con el medio el tiempo programado, porque en esta investigación se construyó un soporte con una malla de plástico, tapada en la parte inferior con papel filtro, para impedir el paso de los embriones a través de la manguera cuando se elimine el medio del frasco; en este caso el papel filtro siempre permaneció húmedo, por ende los callos estuvieron siempre en contacto con residuo de medio de cultivo, lo cual no pasa al utilizar el Sistema de Inmersión RITA.

En el Sistema de Inmersión Casero, sí se obtuvieron resultados; esto pudo deberse a que el callo escogido fue embriogénico y a que la agitación favoreció la producción de embriones, debido a que existe una disgregación de células, por lo cual a los 20 días de cultivo ya se observaron estructuras embriogénicas (embriones en diferentes estados de desarrollo) (Figura 7).

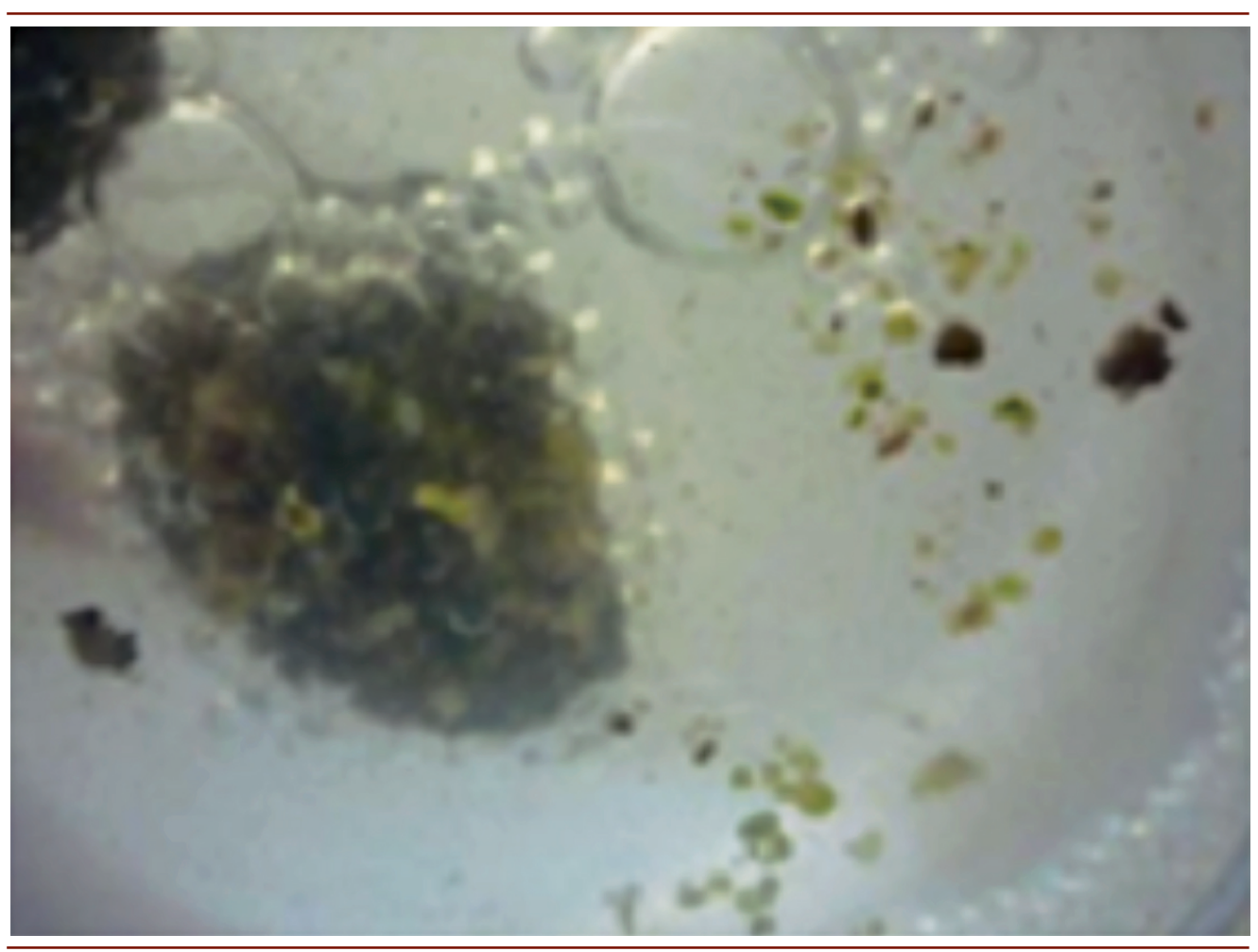

Figura 7. Embriones obtenidos en medio de inducción de callo a la mitad de la concentración (líquido). 
A las 8 semanas se obtuvieron un total de semanas se obtuvieron 611 embriones, 337 embriones, según la Tabla 9 y a las 12 mostrados en la Tabla 10.

\section{Tabla 9}

Conteo de embriones en todos los estados encontrados a las 8 semanas de cultivo en medio líquido en el sistema casero

\begin{tabular}{cc}
$\begin{array}{c}\text { Estado } \\
\text { embrionario }\end{array}$ & $\begin{array}{c}\text { \# de } \\
\text { embriones }\end{array}$ \\
Globular & 193 \\
Corazón & 8 \\
Torpedo & 72 \\
Cotiledonar & 11 \\
Anormales & 53 \\
\hline TOTAL & 337 \\
\hline
\end{tabular}

Tabla 10

Conteo de embriones en todos los estados encontrados a las 12 semanas de cultivo en medio líquido en el sistema casero

\begin{tabular}{cc}
$\begin{array}{c}\text { Estado } \\
\text { embrionario }\end{array}$ & $\begin{array}{c}\text { \# de } \\
\text { embriones }\end{array}$ \\
Globular & 332 \\
Corazón & 14 \\
Torpedo & 147 \\
Cotiledonar & 15 \\
Anormales & 103 \\
\hline TOTAL & $\mathbf{6 1 1}$ \\
\hline
\end{tabular}

Resulta difícil establecer cultivos de independientemente uno del otro, por lo embriones somáticos que mantengan una cual en un mismo tejido podemos tener uniformidad de sus células en el desarrollo embriones somáticos en diferentes etapas de de nuevos clones o individuos, ya que la desarrollo, que se muestran en las Figuras 8 formación de los embriones se produce y 9 (Moncada et al, 2005; Muñoz, 2003). 


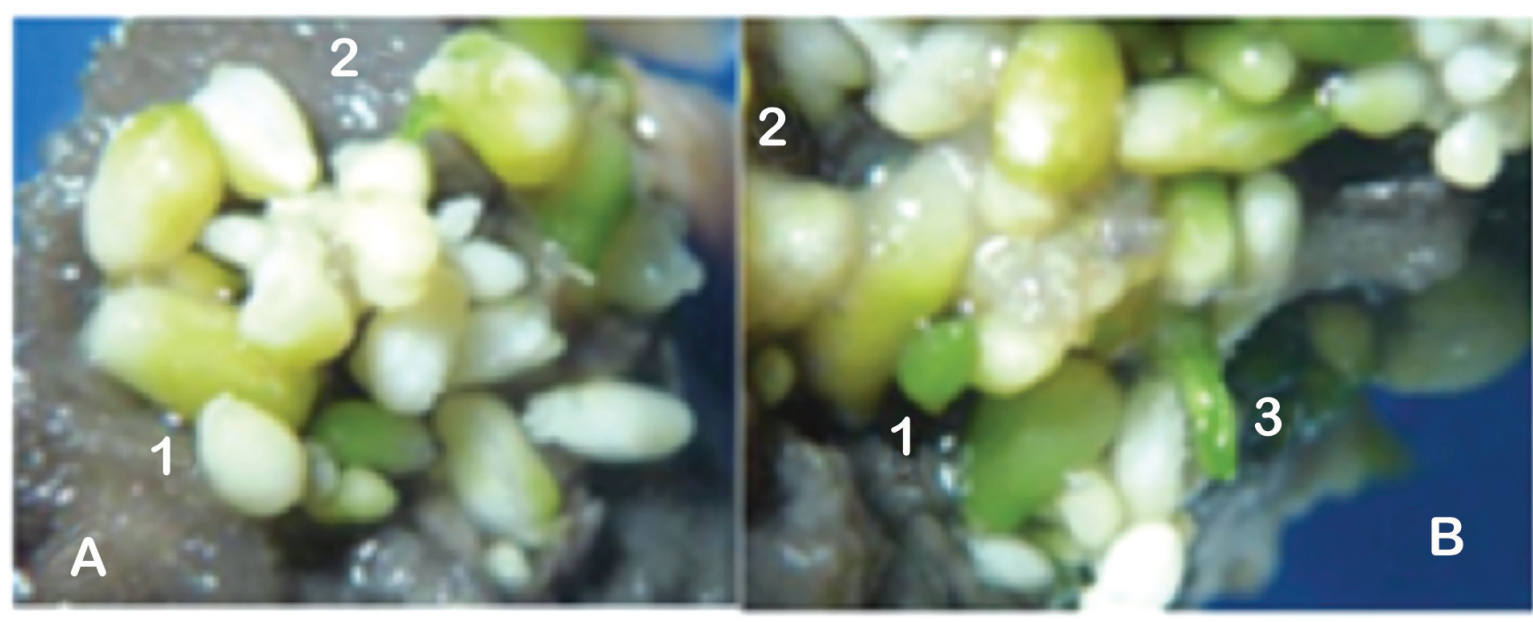

Figura 8. Formación de embriones en medio líquido. A.1) embrión en fase globular. A.2) embrión en fase cotiledonar. B.1) embrión en fase globular. B.2) embrión en fase corazón. B.3) embrión en fase cotiledonar.

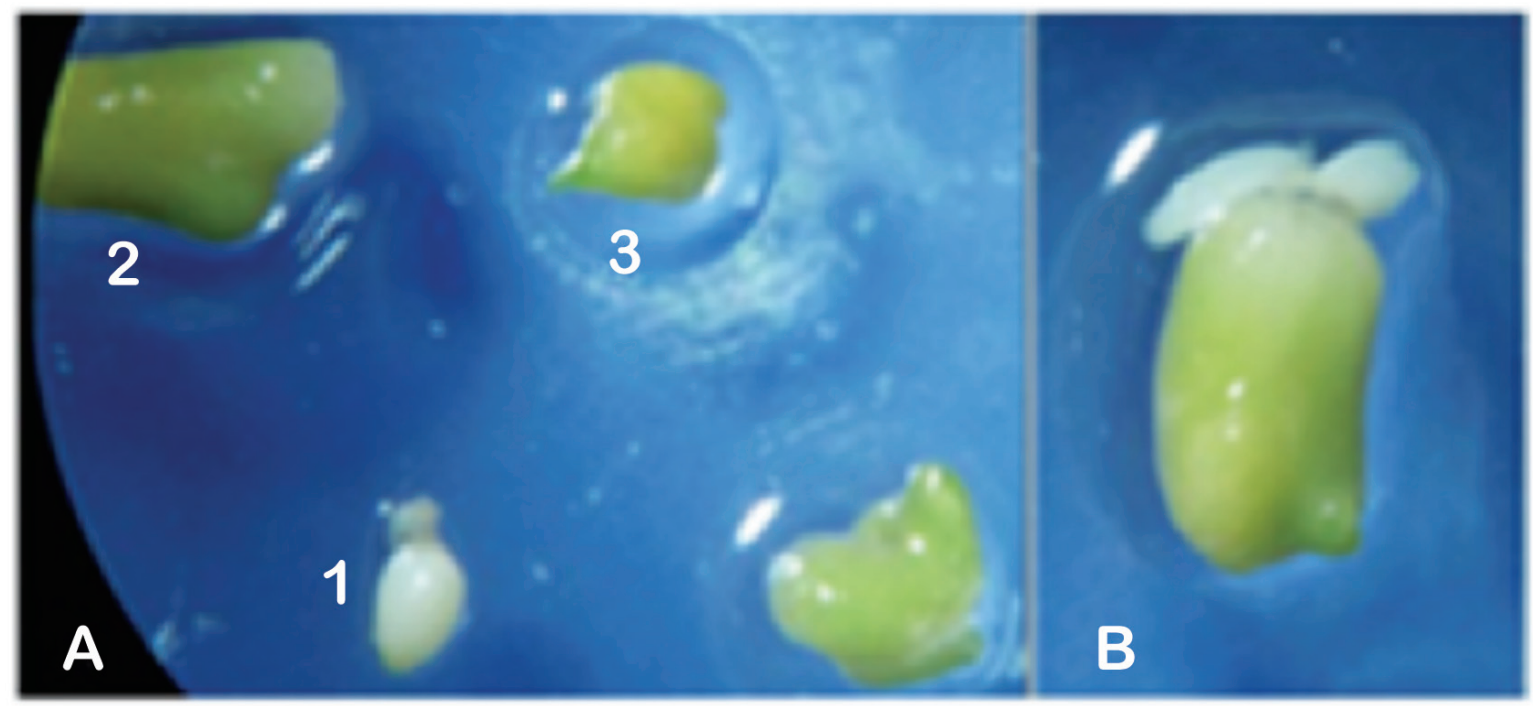

Figura 9. Embriones individuales vistos en el estereoscopio (1.6X). A.1) embrión en estado globular. A.2) e4mbrión en estado corazón. A.3) embrión desarrollando el meristema apical. B) Embriogénesis secundaria.

Además,notodaslascélulasresponden a la formación de embriones somáticos de igual manera, ya que solamente ciertas células parecen estar aptas a responder a la embriogénesis somática debido a la sensibilidad diferencial a los reguladores del crecimiento (González, 2008). Todo lo dicho se comprueba en este estudio ya que a lo largo del cultivo se presentaban diferentes etapas embrionarias (globular, corazón y torpedo). 
Se encontraron malformaciones en el deformaciones, protuberancias, torcedura desarrollo del $16.86 \%$ de los embriones, que del eje radical, detalladas en la Figura 10. presentaron fusiones entre 2 o 3 embriones,

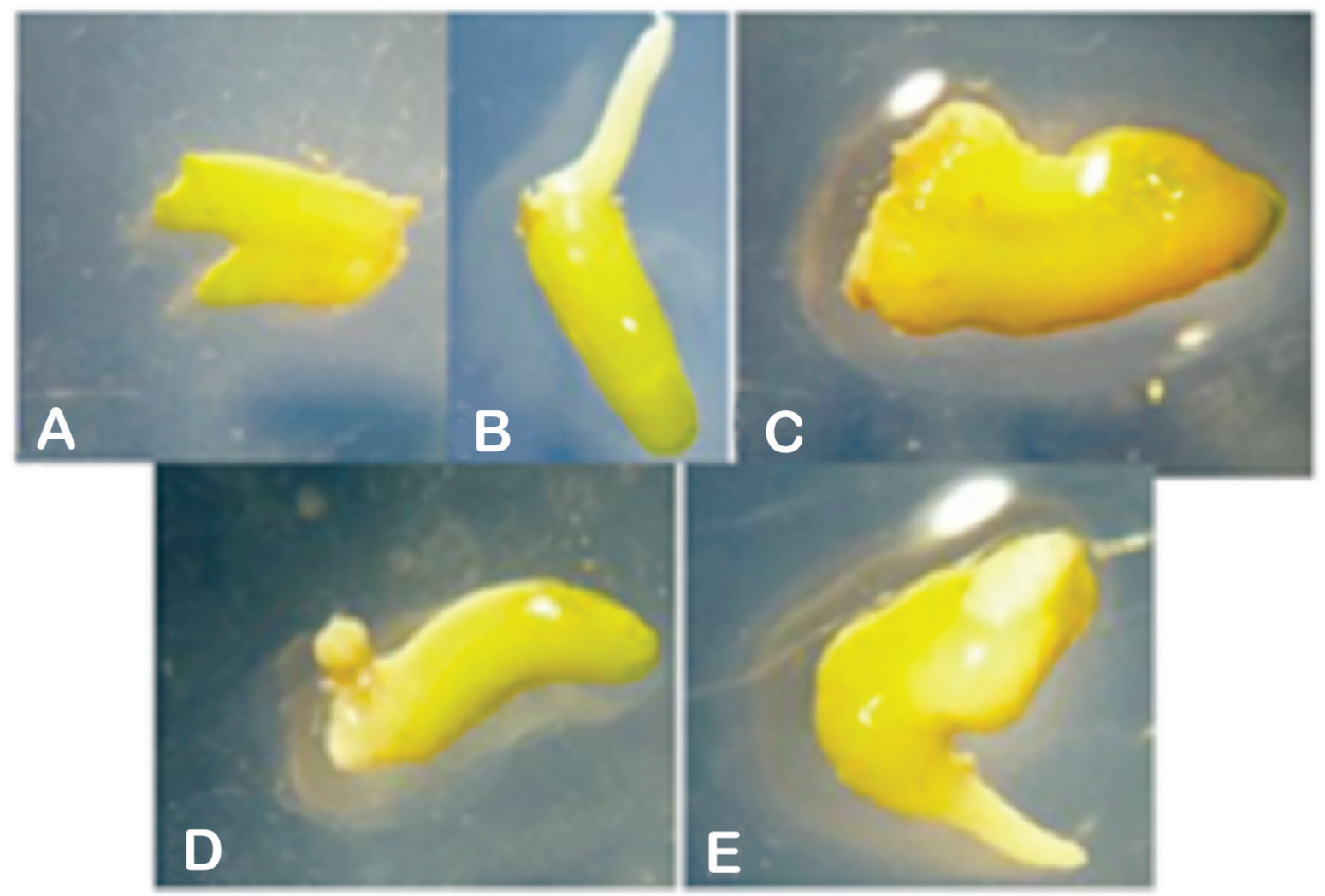

Figura 10. Malformación de los embriones observados en el estereoscopio (1.6X). A) embriones fusionados. B) embrión desarrollando sólo eje radical. C) embrión sin forma específica. D) embrión con protuberancia lateral. E) embrión con torcedura del eje radical.

El uso de medio líquido ha permitido la proliferación y la producción en masa de embriones somáticos en recipientes como erlenmeyers o en biorreactores para C. arabica y C. canephora (Santana, 2004; Quiroz-Figueroa et al., 2002; Von, 2002; Etienne y Berthougly, 2002; Etienne-Barry et al., 1999 y Zamarripa et al., 1991), aunque desafortunadamente existen problemas de calidad en los embriones que pueden ser: anormalidades morfológicas, desarrollo asincronizado y tamaño heterogéneo. Este estudio evidencia dichos problemas en el porcentaje considerablemente alto de embriones anormales que podría deberse a la elevada densidad de embriones en la tarrina o bien a la concentración de reguladores de crecimiento en el medio de cultivo (Barreto, 2003). 


\section{CONCLUSIONES}

- El tratamiento fitosanitario con un fungicida sistémico AMISTAR, al cual fueron sometidas las plantas mantenidas en invernadero ayudó a que exista bajo porcentaje de contaminación en condiciones in vitro.

- El uso de hipoclorito de sodio al $1.5 \%$ con tiempos de inmersión de 15 y 20 minutos, lograron controlar eficientemente la contaminación (0\% de explantes contaminados) y presentaron bajos porcentajes de oxidación (10\%).

- Los biorreguladores de crecimiento 2,4-D y Kinetina resultaron beneficiosos en la inducción de callo de hoja de café y el mejor fue el tratamiento $5\left(0.5 \mathrm{mgL}^{-1} 2,4-\mathrm{D}\right.$ y $\left.2 \mathrm{mgL}^{-1} \mathrm{KIN}\right)$.

- En medio líquido la toma de nutrientes es mucho más eficiente y los embriones se pueden obtener a los 20 días de cultivo.

- El sistema casero, en el cual los callos estuvieron inmersos todo el tiempo en el medio de cultivo, resultó ser más eficiente al momento de generar embriones, en comparación con el SIT automatizado, en donde no se obtuvo ningún resultado, debido a que no se utilizaron callos embriogénicos verificados mediante una prueba histológica y luego a que el sistema no era el adecuado para el desarrollo de la embriogénesis ya que según bibliografía el sistema de inmersión RITA, es el que mejores resultados ha dado en cuanto a producción en masa de embriones somáticos en diferentes especies.

\section{AGRADECIMIENTOS}

A la Escuela Politécnica del Ejército y al Laboratorio de Cultivo de Tejidos Vegetales, que financiaron la presente investigación.

\section{REFERENCIAS BIBLIOGRÁFICAS}

Barreto CA. 2003. Evaluación de tres densidades de siembra y dos frecuencias de inmersión en biorreactor tipo RITA, sobre la calidad morfológica de embriones somáticos de café (Coffea arabica L.) Tesis de Maestría en Ciencias, Centro Agronómico Tropical de Investigación y Enseñanza. Turrialba, Costa Rica.

Cevallos M, Sánchez I y Montes S. 2002. Caracterización Histológica de la Embriogénesis en Coffea canephora P. var. Robusta. Protección Vegetal, 17: 14-19.

De Feria M, Jiménez E, Barbón R, Capote A, Chávez M y Quiala E. 2005. Diferenciación y germinación de embriones somáticos de Coffea arabica L. cv. Catimor 9722 obtenidos en agitador orbital. Biotecnología Vegetal, 5(2): 95-101.

Delgado P, Larco A, García C, Alcívar R, Chilán W y Patiño M. 2002. Café en el Ecuador: Manejo de la broca del fruto /Hypothenemus hampei/ Ferrari. Informe de terminación del proyecto manejo integrado de la broca del café. Página de Internet: 
www.dev.ico.org/projects / cabi_cdrom/PDFFiles/ECUADOR. pdf. Consultada: 20-feb-2012.

Dublin P. 1991. Multiplicación Vegetativa de café, hevea y cacao. En: Cultivo de tejidos en la agricultura: Fundamentos y aplicaciones: 578-619.

Etienne H, Dechamp E, Barry-Etienne D y Bertrand B. 2006. Bioreactors in coffee micropropagation. Plant Physiology, 18(1): 45-54.

Etienne H. 2005. Somatic embryogenesis protocol: Coffee (Coffea arabica L. and Coffea canephora P.). Forestry Sciences, 77: 167-179.

Etienne H y Berthouly M. 2002. Temporary immersion systems in plant micropropagation (review). Plant Cell Tissue and Organ Culture, 69: 215-231.

Etienne-Barry D, Bertrand B, Vásquez N y Etienne H. 1999. Direct sowing of Coffea arabica somatic embryos mass-produced in a bioreactor and regeneration of plants. Plant Cell Reports, 19: 111-117.

Gatica A, Arrieta G y Espinoza A. 2007. Plant regeneration via indirect somatic embryogenesis and optimisation of genetic transformation in Coffea arabica L. cvs. Caturra and Catuai. Electronic Journal of Biotechno$\log y$, 11(1): 101-112.
González O, Morejón O, Hernández M, Coronado M y Silva J. 2008. Estudio histológico de la embriogénesis somática: Una necesidad para el conocimiento de los procesos biotecnológicos y la conservación de la biodiversidad en el cultivo del boniato Ipomoea batatas L. Página de Internet: www.ua.es / es / informacion / biodiversidad / cuadbiod27.pdf. Consultada: 08-marzo-2013.

González M, Ramos R y Santana N. 2004. Efecto del ácido abscísico (ABA) en la regulación del desarrollo de embriones somáticos de Coffea canephora P. Var. Robusta. Cultivos Tropicales, 21(3): 33-37.

González M. 2003. Estudio del proceso de callogénesis en genotipos promisorios de cafeto (Coffea canephora P.). Revista Colombiana de Biotecnología, 1: 16-22.

Girón M. 1998. Desarrollo y Maduración de Embriones Somáticos de Híbridos F1 de Coffea arabica para una Producción Masal. Tesis de Maestría en Ciencias, Centro Agronómico Tropical de Investigación y Enseñanza. Turrialba, Costa Rica.

Moncada E, Vielma M y Mora A. 2005. Inducción in vitro de embriogénesis somática a partir de tejido foliar de Coffea arábica L.Variedad Catuaí Amarillo. Página de Internet: www. oai.saber.ula.ve/cgi-win/be_alex.exe? Acceso $=$ T016300002155 $/ 7 \&$ Nombreb 
$\mathrm{d}=$ ssaber. Consultada: 8-marzo-2013.

Morel G y Wetmore R. 1951. Tissue culture of monocotyledons. American Journal of Botany, 38: 138-140.

Muñoz S. 2003. Embriogénesis somática en Cedro (Cedreña odorata Linnaeus) a partir de cotiledones. Página de Internet: www.lamolina.edu. pe / cirgebb / publicaiones.htm. Consultada: 6-febrero-2012.

Murashige T y Skoog F. 1962. A revised medium for rapid growth and bioassays with tobaco tissue culture. Plant Physiology, 15: 473-497.

Nomura K y Komamine A. 1995. Physiological and biochemical aspects of somatic embryogenesis. In vitro Embryogenesis in plants, 1: 249-265.

Pérez J. 1998. Propagación y mejora genética de plantas por Biotecnología. Primera edición. Instituto de Biotecnología de las Plantas. Villa Clara. 320pp.

Pírela M y Mogollón N. 1996. In vitro propagation of guava (Psidium guajava L.) cv. Mara-7 from stem shoots of cv. Mara-7. Acta Horticulturea, 452: 47-52.

Pro Ecuador. 2013. Guía comercial 2013. Página de Internet: www. proecuador.gob.ec/wp-content/ uploads / downloads / 2013 / 02 / PROEC_GC2013_ECUADOR.pdf.
Roca, W y Mroginski L. 1991. Cultivo de Tejidos Vegetales en la Agricultura: Fundamentos y aplicaciones. Primera edición. Publicación CIAT. Cali. 963 pp.

Rezende A, Pasqual M, Pereira R, Costa J, Bortolotti A y Ferreira L. 2003. Indirect somatic embryogenesis. Ciência e Agrotecnologia, 27(1): 107-116.

Quiroz-Figueroa F, Méndez-Zeel M, Rojas-Herrera R y Loyola-Vargas V. 2002. Histolgical studies on the developmental stages and differentiation of two different somatic embryogenesis systems of Coffea arabica. Plant Cell Reports, 20(12): 1141-1149.

Samson P, Campa C, Le Gal L, Noirot M, Thomas G, Lokeswari T y de Kochko A. 2006. Effect of primary culture medium on high frequency somatic embryogenesis in different Cofee species. Plant Cell, Tissue and Organ Culture, 86: 37-45.

Santana N, González M, Valcárcel M, CantoFlick A, Hernández M, Fuentes-Cerda C, Barahona F, Mijangos-Cortés J y Loyola-Vargas M. 2004. Somatic embryogenesis: a valuable alternative for propagating selected robusta coffee (Coffea canephora) clones. In Vitro Cellular \& Developmental BiologyPlant, 40: 95-101. 
Santana N. 1993. Embriogénesis somática Zamarripa A, Ducos JP, Bollon H, Dufour en el cultivo de cafeto (Coffea sp). Tesis M y Petiard V. 1991. Production de doctorado en Ciencias Agrícolas, d'embryons somatiques de caféier Instituto Nacional de Ciencia Agrícola (INCA). San José de las en milieu liquide: Effets densité Lajas, Cuba.

d'inoculation et renouvellement du milieu. Café, Cacao, Thé, 35(4): 233-243. 